\title{
Sero-prevalence of Hepatitis B virus infection and associated factors among pregnant women attending antenatal care service in health institutions in Gedeo Zone, Southern Ethiopia
}

\section{Mhiret Belay Tadiwos}

South Omo Zone Department of Health, Sothern Ethiopia

Girum Gebremeskel Kanno ( $\sim$ girummeskell@gmail.com )

College of Health and Medical Science, School of public health, Dilla University, Ethiopia https://orcid.org/0000-0001-6689-1983

\section{Abereham Shiferaw Areba}

College of Health and Medical Science, School of public health, Dilla University, Ethiopia

\section{Robel Hussen Kabtyemer}

College of Health and Medical Science, Department of Nutrition, Dilla University, Dilla, Ethiopia

\section{Zeleke Girma Abate}

College of Health and Medical Science, School of Public Health, Dilla University, Ethiopia

\section{Mekonnen Birhanie Aregu}

College of Health and Medical Science, School of public health, Dilla University, Ethiopia

\section{Research Article}

Keywords: Hepatitis B virus, Pregnancy, Sero-Prevalence, Gedio Zone, Ethiopia

Posted Date: September 25th, 2020

DOI: https://doi.org/10.21203/rs.3.rs-80793/v2

License: (c) (i) This work is licensed under a Creative Commons Attribution 4.0 International License. Read Full License

Version of Record: A version of this preprint was published on February 10th, 2021. See the published version at https://doi.org/10.1177\%2F2150132721993628. 


\section{Abstract}

Background: Hepatitis B virus infection is a major public health problem worldwide and is a major cause of morbidity and mortality. This study aimed to assess the prevalence of hepatitis B virus infection and associated factors among pregnant mothers in the Gedeo Zone, southern Ethiopia.

Methods: An institution-based cross-sectional study was conducted in governmental and private health facilities in the Gedeo zone from January to April 2019. The study participants were selected using systematic random sampling techniques. The Eugene strip test was used to determine hepatitis $B$ virus infection among pregnant mothers. The status of HIV was collected from the records. Other variables were collected from the mothers using interviewer-administered questionnaires. Binary logistic regression was used for the analysis. Adjusted odds ratios and their $95 \%$ confidence intervals (Cls) were calculated to determine the association between HBsAg seropositivity and various factors. A p-value of less than 0.05 was considered significant.

Results: The prevalence of hepatitis B virus infection among pregnant mothers was $9.2 \%$ in the Gedeo Zone. Previous history of blood transfusion [AOR=5.2, 95\% Cl: 2.1, 12.5], previous history of hospital admission [AOR=3, 95\% Cl: 1.4,6.6], history of having an abortion [AOR=4.1,95\% $\mathrm{Cl}: 1.5,11.7$ ], age of the pregnant women [AOR=5.1, 95\% Cl: 1.5, 18.0], and HIV status of the mother [AOR=8.1,95\% Cl: 1.9, 36.0] had a statistically significant association with HBsAg seropositivity.

Conclusions: Hepatitis B virus infection was found to have higher endemicity (9.2\%) in the Gedeo Zone which is higher than the national pooled prevalence which was $4.75 \%$. Early initiation of antenatal care services which incorporate the prevention and control of HBV must be implemented by the health facilities in the Gedeo Zone.

\section{Introduction}

Hepatitis $B$ virus (HBV) is a hepatotropic deoxyribonucleic acid (DNA) virus that occurs through the immune-mediated killing of infected liver cells [1]. It is a major blood-borne and sexually transmitted infectious agent and poses a serious global public health problem that is approximately 100 times more contagious than human immunodeficiency virus (HIV) and is found in diverse populations and subpopulations [2-3]. The transmission routs for HBV are mainly linked with parenteral or mucosal exposure to infected blood and body fluids, such as secretions or saliva, unsafe sexual intercourse, and transfusion of HBV-infected blood and blood products through either by vertical or horizontal routes. The transmission of HBV in highly endemic areas mostly results in a high rate of chronic infections [4-6].

Globally, mother-to-child transmission (MTCT) is responsible for approximately one-half of chronic hepatitis $B(\mathrm{CHB})$ infections [7]. It is also associated with a high risk of maternal complications and has effects on both the mother (such as preeclampsia, placenta previa, preterm delivery, placental separation, antepartum hemorrhage, preterm labor, increased incidence of intraventricular hemorrhage, gestational 
diabetes mellitus) and the child (leads to fetal and neonatal hepatitis and a higher risk of developing chronic liver disease and cancer) [8-10].

Infants Born from hepatitis B positive pregnant mothers (both hepatitis B surface antigen (HBsAg) and hepatitis $B$ e antigen ( $\mathrm{HBeAg})$ ), have a higher (70-90\%) risk of acquiring the infection from their mothers and they are about $10-40 \%$ at risk, if the mother tested positive for only HBsAg. In endemic areas, where carrier rates are greater than $5 \%$, perinatal transmission is common, especially when HBV-infected mothers are also HBeAg positive [11-13]. Globally, 350 million people are chronic carriers. Of these, one million are expected to suffer serious illness and death from cirrhosis and hepatocellular carcinoma (HCC), and approximately 600,000 people die annually from acute or chronic complications of hepatitis B infection [14-16].

Africa, which is considered as a region of high endemicity ( $\geq 8 \%$ ), has the second largest number of chronic carriers after Asia [16]. Although it is difficult to assess the exact burden of HBV in Africa, the Sero-prevalence of hepatitis B surface antigen (HBsAg) has been estimated to be in the range from $6 \%$ to $20 \%$ [17-18]. A higher prevalence of 9.7\%-16.6\% was observed in other developing countries [19-22], while the prevalence of HBV in Ethiopia among pregnant women has shown moderate endemicity, with the prevalence of HBsAg positivity ranging from 2.3\%-7.9\% [23-29]. The pooled prevalence for HBV among pregnant mothers in Ethiopia was 4.75\% [30]. Different factors, such as having a history of blood transfusion, history of use of sharp materials, having multiple sexual partners, ear pricing, history of abortion, place of delivery, the practice of female genital mutilation, history of tooth extraction, cesarean section, and tattooing, were some of the major risk factors associated with HBV Ag seropositivity in previous studies in similar settings [23-34].

Since HBV-infected pregnant women are at risk of infecting their babies, knowing the magnitude of HBV status and its risk factors in the area is very important in preventing mother-to-child transmission and reducing the burden of the disease. However, in resource-constrained settings such as Ethiopia, laboratory diagnosis of HBV infection is not part of routine care in ANC of all health facilities, which makes the detection of pregnant mothers with HBV difficult, which also makes the intervention very difficult [35]. Observational community studies of serological markers of HBV infection have an important role in identifying population endemicity and possible routes of transmission that could help in the development of appropriate control measures. Therefore, this study intends to fill the limited information gap regarding the prevalence and associated factors of HBV among pregnant women in the southern part of Ethiopia specifically in the Gedeo Zone.

\section{Methods}

\section{Design and study sites}

This study was an institutional-based cross-sectional study conducted in selected health facilities in Gedeo Zone Southern Nations and nationalities regional state, Ethiopia. The Zone has 1 referral hospital, 
3 primary hospitals (Bule, Gedeb and Yerga Chefe), 38 health centers, 146 health posts, 4 NGO clinics, and 17 reported private health facilities.

\section{Sample size determination and procedure}

The sample size was determined using a single population proportion formula. The sample size was calculated based on the following assumptions: $95 \%$ confidence interval $(\mathrm{Cl})$, hepatitis $\mathrm{B}$ virus prevalence rate $3.5 \%$ [29], degree of precision of $1.75 \%$, and nonresponse rate of $10 \%$. Finally, the calculated sample size was 479 . Out of 42 the public health facilities found in Gedeo Zone, one referral hospital, eleven health centers and 1 primary hospital are selected using lottery method and from 17 private clinic only 5 were giving ANC service at the time of the study and from these 5 private clinic 2 was privet clinics were included in the study using lottery method. Then the total sample size allocated for each facilities proportional to their population size. A list of pregnant mothers from ANC registration in the selected health facilities was used as a sampling frame. Finally the study subjects attending ANC clinic at the time of data collection were selected using systematic random sampling technique as indicated in (Figure 1).

\section{Data collection}

Data was collected from January to March in 2019. Socio-demographic characteristics, such as age, residence, employment status, level of education, and marital status, were collected using a structured questionnaire administered by trained health professionals. The status of HIV of the pregnant women was collected from the records and HBV infection status was determined using the Eugene strip test.

\section{Laboratory analysis}

$3 \mathrm{ml}$ of venous blood drawn under aseptic conditions has transferred to an EDTA (Ethylene diamninetetra acetic acid) tube by trained laboratory personnel. These tubes were labelled and processed at the time of collection. The blood samples taken from the participants was centrifuged at 3000 revolution per minute (RPM) for at least 10 minutes at room temperature. Each serum sample was subjected to the HBsAg antibody rapid test using the test kit (Manufacturer: Shangai Eugene Biotech Co., Ltd. Shangai. China. Email: info@eugenebio.com.).

\section{Data quality assurance}

To ensure the quality of data, the questionnaire was prepared in the English language, translated to Amharic and Gedeofa, and translated back to English by another person who can speak all three languages. Furthermore, the questionnaire was pretested, and field editing was performed to ensure the completeness and correctness of the data. A pretest was conducted on $5 \%$ of the total sample size in Bule Primary Hospital, which was not included in this study. The collected data were checked daily for consistency and accuracy. Standardized procedures were strictly followed during blood sample collection and storage. Known positive and negative samples were run to control the quality of the HBsAg kit as external quality assurance. 


\section{Data processing and analysis}

Data were entered into Epi-Data version 3.1 and transferred to SPSS version 25 for analysis. Binary and multivariable logistic regression analyses were used to determine the association between explanatory variables and the outcome variable using odds ratios at $95 \% \mathrm{Cls}$. Predictor variables with a P-value $<0.25$ in the bivariate analysis were candidates for the multivariable logistic regression model. Adjusted odds ratios and their $95 \%$ confidence intervals (Cls) were calculated to determine the association between HBsAg seropositivity and various factors. A p-value of less than 0.05 was considered significant. The Hosmer-Lemeshow test was used to check the overall model fitness.

\section{Results}

\section{Socio-demographic and obstetric characteristics}

A total of 479 mothers have participated in this study with a mean age 25.9 (SD \pm 5.01 ). The majority of the mothers interviewed 411 (85.8\%) were married, and more than two-thirds of the respondents 185 $(38.6 \%)$ had primary education. More than half of the participants $(245,51.1 \%)$ were housewives, while $265(55.3 \%)$ of the mothers were rural residents. Age between 26 and 30 years was the dominant maternal age group with 151 (31.5\%) mothers, while mothers older than 35 were only $23(4.8 \%)$.

Regarding the obstetric history of the mothers, 121 (25.3\%) had no previous birth history, while the remaining $358(74.7 \%)$ reported that they had multiple pregnancies. Out of 479 pregnant women, 99 $(20.7 \%)$ were in the first trimester, 245 (50.5\%) were in the second trimester, and the rest were in the third trimester. It was assessed that $32(6.7 \%)$ of pregnant women had a history of abortion in the past. Among 479 respondents, 103 mothers had a history of home delivery (21.5\%), and 255 mothers had a history of institutional delivery (52.2\%).

\section{Prevalence of hepatitis B virus among ANCs following pregnancy}

The prevalence of HBV among pregnant mothers who were on ANC follow-up in the Gedeo Zone was $9.2 \%$ during the study period.

\section{Bivariate and Multivariable Analysis}

During the bivariate analysis, a history of blood transfusion, previous history of hospital admission, previous history of abortion, gestational age, previous place of birth, age of the pregnant women, and HIV status of the pregnant women was significantly associated with HBV status of the pregnant women. As indicated, candidates in Table 1 were candidates for the multivariate logistic regression analysis. In the final analysis, women with a previous history of blood transfusion, previous history of hospital admission, previous place of birth, ear-piercing practice, current gestational age, and HIV status of the pregnant women were significant factors that determined the seroprevalence of hepatitis B virus of pregnant women in the Gedeo zone in the multivariable logistic regression. 
Table 1. Bivariate and multivariable logistic analysis of HBV among pregnant women in the Gedeo Zone, Southern Ethiopia 


\begin{tabular}{|c|c|c|c|c|c|}
\hline \multirow[t]{2}{*}{ Variable } & \multicolumn{2}{|l|}{ HBV } & \multirow[t]{2}{*}{ COR } & \multirow[t]{2}{*}{ AOR } & \multirow[t]{2}{*}{$P$-value } \\
\hline & Positive & Negative & & & \\
\hline \multicolumn{6}{|l|}{ Blood transfusion } \\
\hline No & 31 & 398 & 1 & 1 & \\
\hline Yes & 13 & 37 & $4.5(2.2-9.4)$ & $5.2(2.1-12.5)^{\star \star}$ & $<0.001$ \\
\hline \multicolumn{6}{|c|}{ Hospital Admission } \\
\hline No & 27 & 373 & 1 & 1 & \\
\hline Yes & 17 & 62 & $3.8(2.0-7.4)^{\star \star \star}$ & $3.0(1.4-6.6)^{\star \star}$ & 0.006 \\
\hline \multicolumn{6}{|l|}{ Body tattooing } \\
\hline No & 37 & 332 & 1 & 1 & \\
\hline yes & 7 & 103 & $0.6(0.3-1.4)$ & $0.8(0.3-2.1)$ & 0.719 \\
\hline \multicolumn{6}{|c|}{ History of ear piercing } \\
\hline No & 2 & 60 & 1 & & \\
\hline Yes & 42 & 375 & $3.4(0.8-14.2)$ & $4.4(0.9-21.2)$ & 0.067 \\
\hline \multicolumn{6}{|c|}{ History of abortion } \\
\hline No & 37 & 410 & 1 & 1 & \\
\hline Yes & 7 & 25 & $3.1(1.3-7.7)$ & $4.1(1.5-11.7)^{\star \star}$ & 0.008 \\
\hline \multicolumn{6}{|l|}{ Residence } \\
\hline Rural & 29 & 236 & $0.6(0.3-1.2)$ & $1.6(0.8-3.3)$ & 0.220 \\
\hline Urban & 15 & 199 & 1 & 1 & \\
\hline \multicolumn{6}{|l|}{ Gestational age } \\
\hline First trimester & 15 & 84 & $3.3(1.3-8.5)^{\star}$ & $2.7(0.9-8.1)$ & 0.073 \\
\hline Second trimester & 22 & 220 & $1.9(0.8-4.5)$ & $2.1(0.8-5.7)$ & 0.151 \\
\hline Third trimester & 7 & 131 & 1 & 1 & \\
\hline \multicolumn{6}{|c|}{ Age of the pregnant women } \\
\hline$>20$ & 16 & 77 & $2.8(0.98-8.1)$ & $5.1(1.5-18.0)^{\star}$ & 0.011 \\
\hline $20-29$ & 14 & 148 & $1.3(0.4-3.7)$ & $2.0(0.6-6.6)$ & 0.275 \\
\hline $30-39$ & 9 & 142 & $0.9(0.3-2.7)$ & $0.98(0.3-3.5)$ & 0.979 \\
\hline $40-49$ & 5 & 68 & 1 & 1 & \\
\hline
\end{tabular}




\begin{tabular}{|llllll|}
\hline Negative & 39 & 427 & 1 & 1 & \\
\hline Positive & 5 & 8 & $6.8(2.1-21.9)$ & $8.3(1.9-36.0)^{\star \star}$ & 0.005 \\
\hline
\end{tabular}

$* p<0.05, * * p<0.01, * \star * p<0.001$

In the multivariable logistic analysis after controlling for the cofounders, previous history of blood transfusion [AOR=5.2, 95\% Cl: 2.1, 12.5], previous history of hospital admission [AOR=3, 95\% Cl: 1.4, 6.6], history of having an abortion [AOR=4.1,95\% Cl: 1.5, 11.7], age of the pregnant women [AOR=5.1, 95\% Cl: $1.5,18.0]$, and HIV status of the mother [AOR=8.1, 95\% $\mathrm{Cl}: 1.9,36.0]$ were significant factors associated with $\mathrm{HBV}$ infection among pregnant women in the Gedeo Zone.

\section{Discussion}

Surface antigen (HBsAg) can be used as the main marker to indicate the prevalence and endemicity of HBV active infection in the general population in a particular geographical area [36]. In this study area, the overall seroprevalence of HBsAg among pregnant women was $9.2 \%$, which could be considered as a high endemicity area (with seropositivity $\geq 8 \%$ seropositive), based on WHO classification criteria of endemicity of HBV infection [16].

The prevalence was the highest across the country compared to the pooled prevalence indicated by [30] recently. Previous studies in different regions of Ethiopia reported lower proportions, from the lowest prevalence (3.7\%) in Jimma town to the highest (8.4\%) in Dire Dawa [23-29]. However, the finding was lower than findings reported by other developing countries, with (8\%) in Mali [19], (9.7\%) in Cameroon [20], (10.8\%) in Yemen [21], (11.8\%) in Uganda [22], and (16.6\%) in Nigeria [23]. The observed discrepancies in the magnitude of HBV prevalence across different geographical locations and regions might be due to variations in socio-demographic characteristics of the study population, such as socio-cultural, and tribal practices. Moreover, the variation in diagnosis methodologies, level of awareness, and the quality and access to antenatal care service provision might add to the difference.

In this study, except for age of the pregnant women all the other socio-demographic variables such as marital status, residence, educational status and occupation of the pregnant women did not significantly associated with the risk of acquiring HBV infection $(p>0.05)$.

Blood transfusion as an identified well-established risk factor for HBsAg [37], was significantly associated with seropostivity of HBsAg among Pregnant women in the Gedeo Zone. Pregnant women with a previous history of blood transfusion were five times more likely to be infected with HBV than women who had no history of blood transfusion. This result is in accordance with previous similar studies [28, 32-33]. 
In this study, a previous history of hospital admission was associated with HBV among pregnant women. This might be due to poor infection prevention practices among the health facilities during hospital admission and delivery. Previous hospital admissions were one of the predictors in other previous findings [34, 38].

Pregnant women with a history of abortion had four times increased risk of having HBV infection when compared with those who without previous history abortion practice. These could be justified by either the abortion was the result of unsafe sexual encounter which is considered as the predominant mode of transmission path way for Hepatitis B infection among pregnant women or the poor quality of the abortion practices might be the reason for the exposure. This finding was in line with previous findings in different parts in Ethiopia [33,34]. Pregnant women with age less than 20 were more at risk of having unsafe sexual encounters than the other age groups. This could be one prominent reason why history of abortion and being in the age under 20 has similar effect on pregnant mothers' seropostivity for HBsAg. This was similar to the finding reported by [41], where the proportion of HBV infection was significantly higher in the age group 15-17 years old and [34], <25 year old pregnant women.

The HIV status of the pregnant women was another determinant of HBV infection in this study as in findings in other studies [21, 28, 32, and 38]. Since Ethiopia is categorized as a country with a high HIV burden [39] and in a region with a high HBV endemic area [40], the possibility of HBV/HIV co-infection is a more anticipated precedent. Moreover, it was reported that the co-infection of HIV/HBV could greatly facilitate HBV replication and reactivation, leading to higher HBV-DNA levels and reduced spontaneous clearance of the virus [40].

\section{Conclusions}

A higher prevalence (9.2\%) of HBV infection was detected in the study area which is higher than the national pooled prevalence which was $4.75 \%$. This study illustrated that the seroprevalence of HBV infection has significant association with having a history of blood transfusion, hospital admission, HIV positive status, having history of abortion and pregnant women's age in Gedeo zone southern Ethiopia.

To reduce the seroprevalence of HBV infection in the Gedeo Zone, health education on the risk of HIV, abortion and unsafe sex at early age and safety issues during admission to hospitals is needed at the Zonal level and health facility level. The screening of all pregnant women for hepatitis B virus must be integrated in the routine antenatal care services.

\section{Declarations}

\section{Data Availability}

The data sets used and/or analyzed during the current study are available from the corresponding author on reasonable request. 


\section{Disclosure}

The funding body had no role in the design, data collection, analysis, interpretation, and in writing the manuscript of this study.

\section{Conflict of interest}

The authors declare no conflict of interest, financial or otherwise.

\section{Authors' Contributions}

Mhiret Belay Tadiwos: conceptualization, investigation, Project administration, methodology, Formal analysis, analysis, writing original draft.

Girum Gebremeskel Kanno: methodology, data curation, analysis, editing, supervision, writing review \& editing, manuscript preparation.

Abereham Shiferaw Areba: methodology, data curation, analysis, editing, supervision, writing review \& editing, manuscript preparation.

Mekonnen Birhanie Aregu: methodology, data curation, analysis, editing, supervision, writing review \& editing, manuscript preparation.

Robel Hussen Kabtyemer: methodology, data curation, analysis, editing, supervision, writing review \& editing, manuscript preparation.

Zeleke Girma Abate: methodology, data curation, analysis, editing, supervision, writing review \& editing, manuscript preparation.

\section{Acknowledgment}

We would like to forward our deepest gratitude to Dilla University College of Health Sciences and Medicine and NORHED/SENUPH project for their financial support to conduct this research.

\section{Ethical Approval}

Ethical approval of this study was approved after review by the "Dilla University Institutional Research and Ethical Review Board", and the research was carried out only after an ethical letter was obtained with Protocol Unique number 009/19-01. A consent form was provided to all participants, and the purpose and importance of the study were explained to each study participant. To ensure the confidentiality of the participant's information, codes were used instead of the names of the participant. Participants were interviewed alone to maintain privacy. All participants did not pay for the test. Voluntary participation was clearly explained to all the participants that they could choose to participate in before the study. 


\section{References}

1. World Health Organization. Guidelines for the prevention, care, and treatment of persons with chronic hepatitis b infection. Geneva; 2015. http://www.who.int/hiv/topics/ hepatitis/en/.

2. World Health Organization. Emergencies preparedness, response: hepatitis: frequently asked questions [cited $2016 \mathrm{Jul}$ 5]. Available from: http://www.who.int/csr/disease/hepatitis/world_hepatitis_day/question_answer/en/.

3. Mast EE, Margolis HS, Fiore AE, et al. A comprehensive immunization strategy to eliminate transmission of hepatitis $B$ virus infection in the United States: recommendations of the Advisory Committee on Immunization Practices (ACIP) part 1: immunization of infants, children, and adolescents. MMWR Recomm Rep 2005; 54:1-31.

4. Arauz-Ruiz P, Norder H, Robertson BH, Magnius LO. Genotype H: a new Amerindian genotype of hepatitis B virus revealed in Central America. J Gen Virol 2002; 83:2059.

5. Stephen A Contag M. Hepatitis in Pregnancy. Medscape. 2016;3:435-9.

6. Hwang EW, Cheung R. Global epidemiology of hepatitis B virus (HBV) infection. N Am J Med Sci 2011;4:7-13.

7. Navabakhsh, N. Mehrabi, A. Estakhri, M. Mohamadnejad, and H. Poustchi, "Hepatitis B Virus Infection during Pregnancy: Transmission and Prevention," MEJDD, vol. 3, no. 2, pp. 92-102, 2011.

8. Pennap GR, Osanga ET, Ubam A. Seroprevalence of hepatitis b surface antigen among pregnant women attending antenatal clinic in federal medical center Keffi, Nigeria. Res J Med Sci 2011;5:8082.

9. Tse KY, Ho LF, Lao T. The impact of maternal HBsAg carrier status on pregnancy outcomes: casecontrol study. J Hepatol. 2005; 43 Epub 775.

10. Dessie T, Kassu D, Belete T, Tesfaye T (2014). Seroprevalence and transmission of hepatitis B virus among delivering women and their newborn in selected health facilities, Addis Ababa, Ethiopia: a cross sectional study. BMC Res Notes 7:239.

11. Abram SB. Control of Communicable diseases Manual. 16th ed. Am Public Health Assoc. 1995: 250252.

12. Zhang, Z. C., Chen, Z. Li, Y.-H. Wu, and X.-M. Xiao, Individualized management of pregnant women with high hepatitis B virus DNA levels. World Journal of Gastroenterology, vol. 20, no. 34, pp. 1205612061, 2014.

13. Wright T. L. Introduction to chronic hepatitis B infection. American Journal of Gastroenterology 101, no. 1, pp. S1-S6, 2006.

14. Ikobah J, et al. The prevalence of hepatitis B virus infection in Nigerian children prior to vaccine introduction into the National Programme on Immunization schedule. Pan Afr Med J. 2016; 23:128. https://doi.org/10.116 04/pamj.2016.23.128.8756.

15. World Health Organization. Hepatitis B Fact sheet No 204. Available from: URL: http://www.who.int/mediacentre/factsheets/fs204/en/. Accessed $7^{\text {th }}$ Mar 2016. 
16. World Health Organization. Global policy report on the prevention and control of viral hepatitis in WHO member states; 2013 [cited 2016 Jul 5]. Available from: http://apps.who.int/iris/bitstream/10665/85397/ 1/9789241564632_eng.pdf.

17. World Health Organization. Global policy report on the prevention and control of viral hepatitis in WHO member states; 2013 [cited $2016 \mathrm{Jul}$ 5]. Available from: http://apps.who.int/iris/bitstream/10665/85397/ 1/9789241564632_eng.pdf.

18. Kiire CF. The epidemiology and prophylaxis of hepatitis B in sub-Saharan Africa: a view from tropical and subtropical Africa. Gut 1996; 38 Suppl 2:S5-S12.

19. Brett MacLean, Rosanna F Hess, Edward Bonvillain, Joseph Kamate, Daoda Dao, Amy Cosimano, Shannon H. Sero-prevalence of hepatitis B surface antigen among pregnant women attending the Hospital for Women \& Children in Koutiala, Mali; S Afr Med J. 2012; 102:47-49.

20. Andreas A, Besong F, Julius A, Peter N. F and Peter M. N. Prevalence of HBsAg and knowledge about hepatitis B in pregnancy in the Buea Health District, Cameroon: a cross-sectional study; BMC Research Notes 2014, 7:394 http://www.biomedcentral.com/1756-0500/7/394

21. Entisar A Murad, Suad M Babiker, Gasim I Gasim, Duria A Rayis and Ishag Adam Epidemiology of hepatitis B and hepatitis $C$ virus infections in pregnant women in Sana'a, Yemen BMC Pregnancy and Childbirth. 2013; 13:127 http://www.biomedcentral.com/1471-2393/13/127

22. Bayo $P$, Ochola $E$, Oleo $C$, et al. High prevalence of hepatitis $B$ virus infection among pregnant women attending antenatal care: a cross-sectional study in two hospitals in northern Uganda. BMJ Open. 2014; 4: e005889. doi:10.1136/ bmjopen-2014-005889

23. Kolawole OM, Wahab AA, Adekanle DA, Sibanda T, Okoh A. Sero-prevalence of hepatitis B surface antigenemia and its effects on hematological parameters in pregnant women in Osogbo, Nigeria. Virology J. 2012; 9:317.

24. Mohammed A. and Solomon G. Sero-prevalence of HBsAg and its risk factors among pregnant women in Jimma, Southwest Ethiopia. J.Healh Dev. 2005; 19(1)

25. Abayneh T. T, Misanew A. T, Desta Hiko, C. F, and Gemechu K. J. Sero-prevalence of hepatitis B virus and associated factors among pregnant women in Gambella hospital, South Western Ethiopia: facility-based cross-sectional study; BMC Infectious Diseases (2019) 19:602

26. Yeshi M, Walelign D, Ibrahim A, Anteneh A. Seroprevalence and associated risk factors of hepatitis $B$ virus among pregnant women in southern Ethiopia: a hospital-based cross-sectional study; Epidemiology and Health. 2016; Volume: 38, Article ID: e2016027, http://dx.doi.org/10.4178/epih.e2016027

27. Anteneh A, Getachew F, Setegn E, Agete T, and Demissie A. Prevalence, Infectivity, and Associated Risk Factors of Hepatitis B Virus among Pregnant Women in Yirgalem Hospital, Ethiopia: Implication of Screening to Control Mother-to-Child Transmission Hindawi Journal of Pregnancy. 2018; Volume 2018, Article ID 8435910, 8 pages https://doi.org/10.1155/2018/843591

28. Getahun T, Kasiye S and Firehiwot T. Sero-prevalence of Hepatitis B Virus Infection and Associated Factors among Pregnant Women Attended Antenatal Care Services in Harar City, Eastern Ethiopia; J 
Women's Health Care. 2018; 7:3 DOI: 10.4172/2167-0420.1000436

29. Asrat C, Aman $Y$ and Amsalu A. (2017). Seroprevalence of Hepatitis B virus surface antigen, and factors associated among pregnant women in Dawuro zone, SNNPR, Southwest Ethiopia. BMC Res Notes. 2017; 10:418

30. Alemu A A, Zeleke L B, Aynalem B Y, and Kassa G M. Hepatitis B Virus Infection and Its Determinants among Pregnant Women in Ethiopia: A Systematic Review and Meta-Analysis. Hindawi, Infectious Diseases in Obstetrics and Gynecology Volume 2020, Article ID 9418475, https://doi.org/10.1155/2020/9418475

31. Mekonnen R, Admasu D, Belete M. Sero-Prevalence of Hepatitis B Virus and Associated Factors Among Pregnant Mothers Attending Antenatal Care in Public Health Facilities, Dire Dawa. J Med Microb Diagn. 2018; 7: 281. doi:4172/2161-0703.1000281

32. Getnet G, Fikadu W, Almaz A. and Kihinetu G. Risk factors associated with hepatitis B virus infection among pregnant women attending antenatal clinic at Felegehiwot referral hospital, Northwest Ethiopia: an institution based cross-sectional study BMC Res Notes. 2019; 12:509

33. Temesgen A. B. and Andamlak D. E. Sero-epidemiological patterns and predictors of hepatitis B, C, and HIV viruses among pregnant women attending antenatal care clinic of Atat Hospital, Southern Ethiopia; SAGE Open Medicine. 2020; Volume 8: 1-9 DOI: 10.1177/2050312119900870

34. Geta M, Ayalew G, Yizengaw E, Mihret A, Aseffa A, Howe R, Moges F, Abate E. Seroprevalence of hepatitis $b$ virus infection and associated factors among mothers in Gondar, north-west Ethiopia: a population-based study. Ethiop Med J; 2019:2:97-106

35. Introduction of hepatitis B vaccine into childhood immunization services. 2001.

36. Shepard CW, Simard EP, Finelli L, Fiore AE, Bell BP. Hepatitis B virus infection: epidemiology and vaccination. Epidemiologic Reviews. 2006; 28 (1):112-125.

37. Cisneros-Castolo M, Hernández-Ruiz L, Ibarra-Robles IE, Fernandez-Garate RH, Escobedo-De La Peña $\mathrm{J}$ : Prevalence of hepatitis B virus infection and related risk factors in a rural community of Mexico. Am J Trop Med Hyg 2001, 65:759-763.

38. Mortada EL-S, Mohamed F.M, Mona Salah El. D. H, Mohamed E, Shaimaa S. K. and H. El-K. Prevalence of Hepatitis B Virus Infection among Egyptian Pregnant Women - A Single Center Study International Journal of TROPICAL DISEASE \& Health. 2013; 3(2): 157-168,

39. Ministry of health (MOH): Guidelines for Management of Opportunistic Infections and ART in Adolescents and Adults in Ethiopia. Federal Ministry Of Health 2007

40. Martin C, Lilian H, Irma E, Ibarra R, Irma H, Fernandez G, Jorge E: Prevalence of HBV infection and risk factors in a rural community of Mexico. Am J trop Med Hyg 2001, 65(6):759-763.

41. Mulu W, Zenebe Y, Abera B, Yimer M and Hailu T. Prevalence of human immunodeficiency virus and hepatitis $B$ virus infections in young women seeking abortion care in Ethiopia: a cross - sectional study. BMC Public Health. 2016; 16:996 DOI 10.1186/s12889-016-3658-9

\section{Figures}




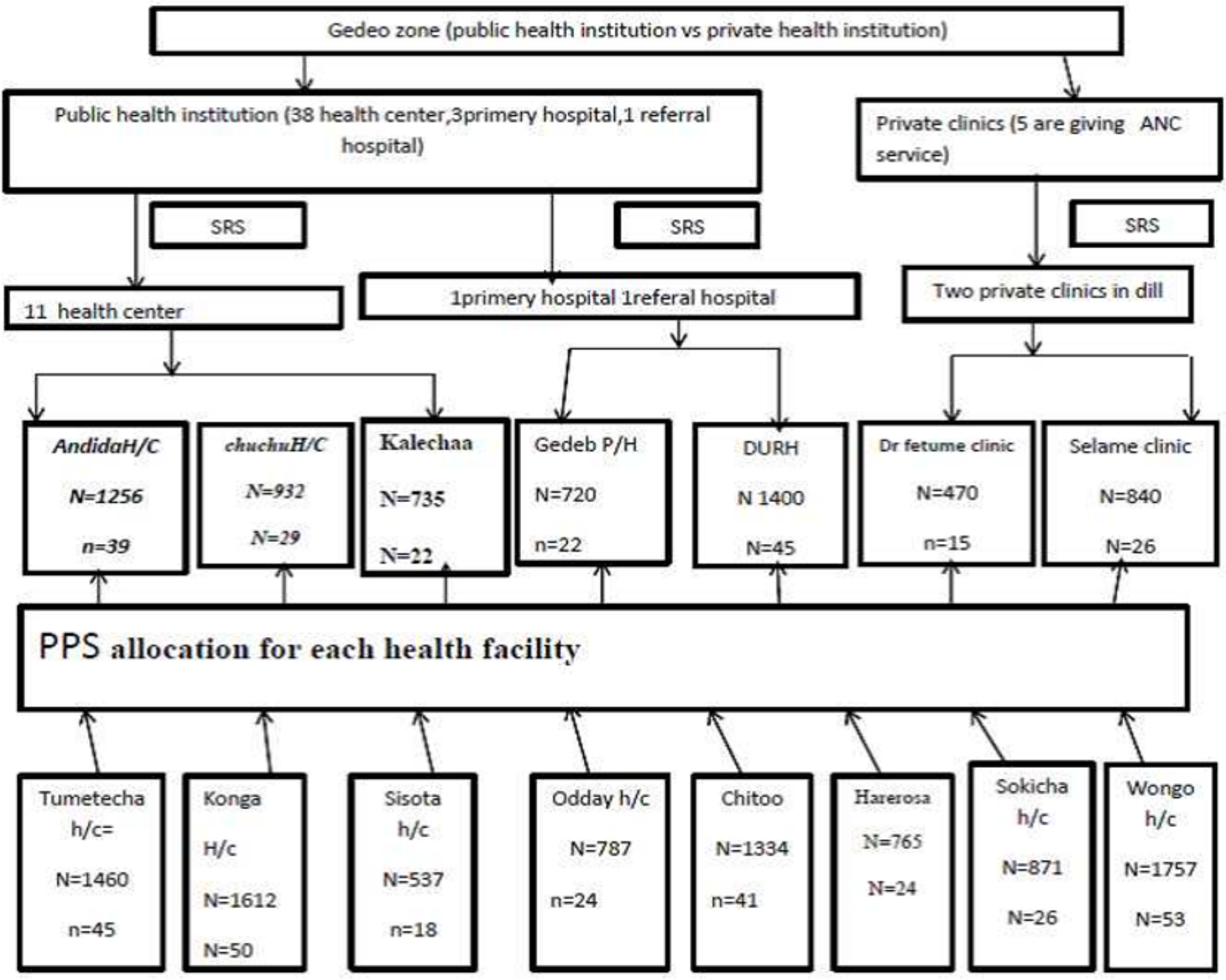

Figure 1

Procedure for selecting study participants from health institutions 